\title{
Tree Response to Herbivory Is Affected by Endogenous Rhythmic Growth and Attenuated by Cotreatment With a Mycorrhizal Fungus
}

\author{
Michael Bacht, ${ }^{1}$ Mika T. Tarkka, ${ }^{2,3}$ Iván Fernández López, ${ }^{2,3}$ Markus Bönn,, ${ }^{2}$ Roland Brandl, ${ }^{1}$ \\ François Buscot, ${ }^{2,3}$ Lasse Feldhahn, ${ }^{2}$ Thorsten E. E. Grams, ${ }^{4}$ Sylvie Herrmann, ${ }^{2}$ and Martin Schädler ${ }^{3,5,+}$ \\ ${ }^{1}$ Animal Ecology, Department of Ecology, Faculty of Biology, Philipps-Universität Marburg, Karl-von-Frisch Str. 8, 35032, \\ Marburg, Germany \\ ${ }^{2}$ Department of Soil Ecology, UFZ-Helmholtz Centre for Environmental Research, Theodor-Lieser-Str. 4, 06120 Halle/Saale, \\ Germany \\ ${ }^{3}$ German Centre for Integrative Biodiversity Research (iDiv) Halle-Jena-Leipzig, Deutscher Platz 5e, 04103 Leipzig, Germany \\ ${ }^{4}$ Ecophysiology of Plants, Technical University Munich, Hans-Carl-von-Carlowitz-Platz 2, 85354 Freising, Germany \\ ${ }^{5}$ Department of Community Ecology, UFZ-Helmholtz Centre for Environmental Research, Theodor-Lieser-Str. 4, 06120 \\ Halle/Saale, Germany
}

Accepted 12 February 2019.

Herbivores and mycorrhizal fungi interactively influence growth, resource utilization, and plant defense responses. We studied these interactions in a tritrophic system comprising Quercus robur, the herbivore Lymantria dispar, and the ectomycorrhizal fungus Piloderma croceum under controlled laboratory conditions at the levels of gene expression and carbon and nitrogen $(\mathrm{C} / \mathrm{N})$ allocation. Taking advantage of the endogenous rhythmic growth displayed by oak, we thereby compared gene transcript abundances and resource shifts during shoot growth with those during the alternating root growth flushes. During root flush, herbivore feeding on oak leaves led to an increased expression of genes related to plant growth and enriched gene ontology terms related to cell wall, DNA replication, and defense. $\mathrm{C} / \mathrm{N}$ allocation analyses indicated an increased export of resources from aboveground plant parts to belowground. Accordingly, the expression of genes related to the transport of carbohydrates increased upon herbivore attack in leaves during the root flush stage. Inoculation with an ectomycorrhizal fungus attenuated these effects but, instead, caused an increased expression of genes related to the production of volatile organic compounds. We conclude that oak defense response against herbivory is strong in root flush at the transcriptomic level but this response is strongly inhibited by inoculation with ectomycorrhizal fungi and it is extremely weak at shoot flush.

${ }^{\dagger}$ Corresponding author: M. Schädler; martin.schaedler@ufz.de

Funding: Funding was provided by the German Research Foundation (Deutsche Forschungsgemeinschaft; SCHA 1242/4-1) and by the German Centre for Integrative Biodiversity Research-iDiv, Halle-Jena-Leipzig (FlexPool project "PlastOak" 34600565-02).

*The $\boldsymbol{e}$-Xtra logo stands for "electronic extra" and indicates that five supplementary figures and five supplementary tables are published online.

The author(s) declare no conflict of interest.

(c) 2019 The American Phytopathological Society
Keywords: fungus-plant interactions, genomics, metabolomics, plant defense mechanisms, proteomics.

Plants growing in natural environments interact with an intriguing diversity of organisms. Among the most common interactions of plants are those with herbivorous insects and mycorrhizal fungi, which have important consequences for the performance of individual plants, dynamics of plant populations, as well as for the composition and structure of plant communities (Crawley 1996; Schädler et al. 2004; Smith and Read 2010; van der Heijden and Sanders 2002). Under natural conditions, both types of interaction simultaneously affect the physiology and growth of the host plant. The underlying genetic and physiological pathways induced by and involved in the above- and belowground interactions seem to overlap (Schenk et al. 2008). However, the simultaneous and concerted influence of these interactions on plant performance is still poorly understood.

Most research on interactions between plants, herbivores, and root symbionts has concentrated on herbaceous plants and arbuscular mycorrhizal fungi. Trees have been mostly neglected in such studies, even though they generally harbor a high density and diversity of insect herbivores (Brändle and Brandl 2001). Furthermore, the majority of trees in boreal and temperate regions $(>95 \%)$ are associated with ectomycorrhizal fungi (Baar et al. 1999; Kõljalg et al. 2000; Smith and Read 2010; Taylor 2002), which are key elements of forest nutrient cycles and, therefore, important drivers of processes and services of forest ecosystems (Read et al. 2004). Thus, the threepartite relationship between insects, trees, and mycorrhizal fungi is a widespread multitrophic interaction with a high ecological and economic relevance.

Furthermore, insect herbivores and mycorrhizal fungi have indirect plant-mediated effects on each other. Mycorrhizal fungi provide nutrients to plants, thereby increasing host plant vigor and nutritional quality which, in turn, can increase the performance of insect herbivores (Borowicz 1997; Gehring and Whitham 1994; Kempel et al. 2010). This resource supply may also allow plants to invest more into resistance against generalist insect herbivores (Bi et al. 2007; Gange and West 1994; 
Halldórsson et al. 2000; Jones and Last 1991; Kempel et al. 2010; Yao et al. 2007). Several authors, however, have observed that this protective effect cannot be attributed only to the improved nutritional status (Fritz et al. 2006) because belowground mutualists also may affect the plant's defensive phenotype in multiple and interacting ways (Schädler and Ballhorn 2017). Mycorrhizal fungi should enable the plant to express defense responses even under conditions where they do not provide a nutritive benefit. In addition, the premycorrhizal phase of the interaction between ectomycorrhizal fungi and tree roots is already accompanied by the stimulation of plant growth and enhanced photosynthesis (Felten et al. 2009; Herrmann et al. 2004). The impact of this premycorrhizal phase on aboveand belowground plant morphology is strong in oak trees (Herrmann et al. 1998), including modifications of gene expression patterns (Frettinger et al. 2007). Because plant defense responses are triggered by modifications in the crosstalk between salicylic and jasmonic acid already in the premycorrhizal stages of the mycorrhizal symbiosis (Pozo and Azcón-Aguilar 2007), corresponding effects on herbivores can be expected.

First analyses of gene expression have demonstrated that herbivores can influence the transcription of hundreds of plant genes (Baldwin et al. 2001; Hermsmeier et al. 2001; Roda and Baldwin 2003; Schmidt et al. 2005). Herbivory can even lead to complete changes in metabolic organization (Hui et al. 2003) and can influence the expression of genes involved in regulation of photosynthesis and pathogen resistance (Hermsmeier et al. 2001). Also, interactions between plants and mycorrhizal fungi lead to important changes in gene expression in the host plant (Frettinger et al. 2007; Herrmann et al. 2015; Tarkka et al. 2013; Volpin et al. 1994; Wiemken and Boller 2002). Many of those genes are important for resource allocation and responses to abiotic and biotic stresses (Herrmann and Buscot 2007; Liu et al. 2007). Thus, not only an overlap in the impact of both types of interaction but also interactive effects on gene expression patterns can be expected.

Quercus robur is characterized by an endogenous rhythmic growth (ERG); in saplings and adult trees, root flushes (RF) and shoot flushes (SF) occur in a rhythmic alternating pattern of stem extension or leaf expansion and root growth (Harmer 1990; Herrmann et al. 2015). These growth flushes are characterized by defined stages which are not only distinguishable by morphological traits but also play an important role in the physiology and ecology of the plant. Most importantly, carbon (C) is allocated to the shoot during SF and to the roots during RF (Herrmann et al. 2015, 2016), which is also reflected by the concentration of nonstructural carbohydrates in the roots (Angay et al. 2014). Such patterns of rhythmic allocation shifts may have a crucial impact on plant response to herbivore feeding. For example, the allocation of resources to above- or belowground parts of plants during the specific growth phases might have consequences for the plant's ability to respond to herbivory. In turn, in response to herbivory, plants can vary the allocation of resources according to conflicting ecological, morphological, and physiological demands within the plant (Schultz et al. 2013). Thus, if there is an increased demand for the production of defense-related compounds in leaves, the amount of $\mathrm{C}$ deposited in fine roots of trees can be reduced, whereas especially herbaceous plants suffering high biomass losses due to herbivory often tend to allocate resources belowground (Frost and Hunter 2008) which, in turn, should influence the interaction between mycorrhizal fungi and host plants. This ERG is regulated by plant internal clocks and accompanied by changes in the expression patterns of numerous genes related to a multitude of metabolic and physiological processes (Herrmann et al. 2015). Thus, differing gene expression patterns during the single growth stages can be expected to have consequences for interactions with other biota (Herrmann et al. 2016). For instance, Kurth et al. (2015) and Maboreke et al. (2016) showed that more genes involved in defense and cell wall remodeling were differentially expressed in oak roots during SF in response to belowground interactors. This implies that the nongrowing roots at this stage are able to invest more into defense responses rather than growth processes (Kurth et al. 2015). Therefore, it might be hypothesized that the pattern is reversed for leaf herbivory, with stronger expression of defense-related genes during the RF. The mediation of the tripartite relationship between plants, mycorrhizal fungi, and insect herbivores by plant growth stages is, furthermore, an unexplored possible source of variability in the outcomes of this multitrophic interaction. To understand the underlying effects of the ectomycorrhizal fungus on the host plant, an analysis of ongoing transcriptional and nutritional changes in this type of multitrophic interaction has to be performed.

Here, we report a controlled laboratory study of the interactions of the pedunculate oak clone DF159 microcuttings (Herrmann et al. 1998), the larva of the herbivore Lymantria dispar, and inoculation with the ectomycorrhizal fungus Piloderma croceum at the levels of gene expression in leaves and whole-plant $\mathrm{C}$ and nitrogen $(\mathrm{C} / \mathrm{N})$ allocation. We studied gene expression in $Q$. robur DF159 leaves using the DF159-specific developed reference transcriptome OakContigDF159.1 of the TrophinOak project (Tarkka et al. 2013). We tested the following hypotheses:

i) We expect that oak trees differentially express defenserelated genes in leaves when they are attacked by insect herbivores, particularly when the trees are interacting with mycorrhizal fungi.

ii) We expect that the gene expression pattern in response response to leave herbivory is stronger in RF, when the leaves are not growing.

iii) We expect that insect herbivory negatively affects $\mathrm{C}$ allocation to roots, and this will be more pronounced in RF when roots are the main $\mathrm{C}$ sink.

iv) We expect that modification in the gene expression patterns related to the ERG reflects the modifications in allocation patterns.

\section{RESULTS}

\section{Plant biomass.}

Dry biomass of oak microcuttings during RF was higher than during SF (Table 1) in all plant fractions, except for lateral roots and source leaves. All microcuttings exposed to herbivory were damaged by the caterpillars. However, herbivory by $L$. dispar alone had no significant effect on plant biomass when compared with the control (Table 1), which indicated that biomass removal by the herbivore was not substantial. Biomass changes of oak in response to feeding by $L$. dispar were further not altered by $P$. croceum inoculation or plant developmental stage (Supplementary Figs. S2 and S3; Table 1). The duration of the experiment was too short to allow the development of visible signs of mycorrhiza formation. However, already during the premycorrhizal phase, $P$. croceum treatment increased both the root and shoot biomass significantly (three-way analysis of variance [ANOVA]) (Table 1). The biomass of source leaves and lateral roots of microcuttings in RF were significantly higher than those in SF, and the biomass of sink leaves of these microcuttings were significantly lower than that in SF (threeway ANOVA; factor stage, RF versus SF) (Table 1).

\section{${ }^{13} \mathrm{C}$ and ${ }^{15} \mathrm{~N}$ in plant tissue.}

Sink leaves of microcuttings exposed to herbivory had significantly lower levels of both ${ }^{13} \mathrm{C}$ and ${ }^{15} \mathrm{~N}$, and lateral roots of 
microcuttings exposed to $P$. croceum inoculation had significantly higher levels of both ${ }^{13} \mathrm{C}$ and ${ }^{15} \mathrm{~N}$ (Table 2; Figs. 1 and 2). The growth stage had a significant effect on the incorporation of ${ }^{13} \mathrm{C}$ and ${ }^{15} \mathrm{~N}$, with significantly more ${ }^{13} \mathrm{C}$ and ${ }^{15} \mathrm{~N}$ incorporated in principal roots during RF. Herbivory by L. dispar reduced ${ }^{13} \mathrm{C}$ and ${ }^{15} \mathrm{~N}$ accumulation in sink leaves and stems but increased ${ }^{15} \mathrm{~N}$ accumulation in source leaves. $P$. croceum inoculation and L. dispar herbivory had a combined effect on the incorporation of ${ }^{13} \mathrm{C}$ and ${ }^{15} \mathrm{~N}$ only in stems with significantly more ${ }^{13} \mathrm{C}$ and ${ }^{15} \mathrm{~N}$ incorporated compared with the effect of each factor alone. $P$. croceum also had a negative effect on the incorporation of ${ }^{15} \mathrm{~N}$ in stems and a positive effect on the incorporation of ${ }^{15} \mathrm{~N}$ in source leaves (Table 2). The effects of herbivory and fungal inoculation were not significantly mediated by the developmental stage.

\section{Gene expression.}

Twenty-four RNA templates were used to prepare cDNA libraries, which were subjected to paired-end RNA sequencing

Table 1. Effects of the factors stage (root flush versus shoot flush), inoculation with Piloderma croceum, Lymantria dispar (herbivory by larvae of Lymantria dispar), and interaction of P. croceum and L. dispar on biomass, analyzed in a three-way analysis of variance ${ }^{\mathrm{a}}$

\begin{tabular}{|c|c|c|c|c|c|}
\hline \multirow[b]{2}{*}{$\begin{array}{l}\text { Plant fraction } \\
\text { (dry mass) }\end{array}$} & \multicolumn{4}{|c|}{$t$ values } & \\
\hline & Stage & P. croceum & L. dispar & $\begin{array}{l}\text { P. croceum/ } \\
\text { L. dispar }\end{array}$ & $n$ \\
\hline Sink leaves & 2.19* & 1.46 & -1.48 & 0.55 & 71 \\
\hline Source leaves & $-4.68 * * *$ & $3.27 * *$ & 1.18 & -1.9 & 71 \\
\hline $\begin{array}{l}\text { Total above } \\
\text { ground }\end{array}$ & $-4.06 * * *$ & $3.86 * * *$ & 0.48 & -1.76 & 71 \\
\hline Lateral roots & -1.28 & $3.45 * * *$ & 0.11 & -0.9 & 71 \\
\hline Principal roots & $-2.17 *$ & 1.09 & 0.51 & -0.87 & 71 \\
\hline $\begin{array}{l}\text { Total below } \\
\text { ground }\end{array}$ & $-2.17 *$ & $2.83 * *$ & 0.39 & 1.11 & 71 \\
\hline
\end{tabular}

a Interactions with the factor stage were not significant and are not presented. The $t$ values were calculated using the $1 \mathrm{~m}$ function implemented in $\mathrm{R}$; significant $t$ values are in bold, signs indicate direction of the effects, and signs for the factor stage indicate the direction of shoot flush $(* * *, * *$, and * indicate $P<0.001,0.01$, and 0.05 , respectively).

Table 2. Effects of the factors stage (root flush versus shoot flush), inoculation with Piloderma croceum, Lymantria dispar (herbivory by third instar larvae of Lymantria dispar), and interaction of $P$. croceum and $L$. dispar on incorporation of ${ }^{13} \mathrm{C}$ and ${ }^{15} \mathrm{~N}^{\mathrm{a}}$

\begin{tabular}{|c|c|c|c|c|c|}
\hline \multirow[b]{2}{*}{ Plant fraction } & \multicolumn{4}{|c|}{$t$ values } & \multirow[b]{2}{*}{$n$} \\
\hline & Stage & P. croceum & L. dispar & $\begin{array}{l}\text { P. croceum/ } \\
\text { L. dispar }\end{array}$ & \\
\hline \multicolumn{6}{|l|}{${ }^{13} \mathrm{C}$ excess } \\
\hline Sink leaves & 0.44 & -1.01 & $-2.91 * *$ & 1.82 & 39 \\
\hline Source leaves & -0.90 & 1.68 & 1.40 & -1.38 & 44 \\
\hline Stem & -1.15 & -0.40 & $-2.61 * *$ & $1.95^{(*)}$ & 40 \\
\hline Lateral roots & -0.28 & $4.27 * * *$ & 1.67 & -0.50 & 45 \\
\hline Principal roots & $-2.92 *$ & -1.60 & 0.44 & -0.95 & 45 \\
\hline \multicolumn{6}{|l|}{${ }^{15} \mathrm{~N}$ excess } \\
\hline Sink leaves & $1.94^{(*)}$ & -0.63 & $-2.65 *$ & 1.04 & 39 \\
\hline Source leaves & -1.28 & $3.19 * *$ & $1.99(*)$ & -1.25 & 44 \\
\hline Stem & -1.31 & $-6.01 * * *$ & $-4.21 * * *$ & $4.75 * * *$ & 41 \\
\hline Lateral roots & -1.02 & $3.80 * * *$ & 1.08 & 0.20 & 44 \\
\hline Principal roots & $-2.05 *$ & 0.04 & 0.49 & -0.93 & 44 \\
\hline
\end{tabular}

a Interactions with the factor stage were not significant and are not presented. Values were log-transformed prior to analyses; significant $t$ values are in bold, signs indicate direction of the effects, and signs for the factor stage indicate the direction of shoot flush $\left(* * *, * *, *\right.$, and ${ }^{(*)}$ indicate $P<$ $0.001,0.01,0.05$, and 0.1 , respectively).
(RNA-Seq). On average, 17,196,808 clean reads were obtained and $14,392,437(84 \%)$ of these reads mapped against the OakContigDF159.1 reference transcriptome (Supplementary Table S1).

The highest number of contigs representing differentially expressed genes (DEG) $(n=4,447)$ was observed in source leaves of RF plants subjected to herbivory only, with 1,082 upregulated and 3,365 downregulated contigs (Fig. 3A; Supplementary Table S2). In contrast, lower levels of DEG were found with the inoculation with $P$. croceum only $(n=396)$ and for plants subjected to both $P$. croceum and $L$. dispar $(n=512)$. In microcuttings in sink leaves at SF (Fig. 3B), significantly lower numbers of contigs were detected, with 80 DEG at $L$. dispar, 56 at $P$. croceum, and 50 at cotreatment. Differential expression of 10 contigs was confirmed by quantitative reversetranscription polymerase chain reaction (qRT-PCR) analysis (Supplementary Table S4; Supplementary Fig. S4).

Both the gene ontology (GO) term enrichment analysis (Fig. 2) and analysis of KEGG pathways (Supplementary Fig. S5) of samples in RF revealed that a strong enrichment of DEG related to growth and development, DNA replication, transcription, and translation. Furthermore, induced DEG involved in cell wall components and other aspects of growth were enriched in $\mathrm{RF}$ in response to herbivory, whereas those assigned to catabolism, photosynthesis, chlorophyll binding, starch biosynthesis, and cell components were depleted (Fig. 4).

GO term enrichment was not as strong for sink leaves of plants in SF compared with plants in RF. In leaves of SF plants subjected to herbivory, the GO term enrichments indicated a focusing on direct defense mechanisms (e.g., chitin catabolism and killing cells of other organisms) (i.e., pathogenesis related such as thaumatin-like protein). In leaves of plants subjected to inoculation with $P$. croceum and plants subjected to $L$. dispar, the GO term for apoplast (a cell component) was depleted. Along with the ${ }^{13} \mathrm{C}$ and ${ }^{15} \mathrm{~N}$ allocation results, for RF plants, we found enrichments in GO terms related to starch biosynthesis in oak inoculated with $P$. croceum and exposed to herbivory, which was depleted in oak plants exposed to herbivore feeding alone. Furthermore, the term nitrate reductase complex was depleted in SF plants but enriched in RF plants. We found terms related to physiological functions as photosynthesis mainly depleted in leaves of oak exposed to herbivory, which was in line with a significant reduction of ${ }^{13} \mathrm{C}$ incorporation.

Analysis of the KEGG pathways (Kanehisa et al. 2014) revealed a pattern similar to that obtained in the GO enrichment analysis. Most of the enriched pathways induced by herbivory were found during RF when subjected to $L$. dispar, and included pathways of amino acid metabolism and nucleotide metabolism. The depleted pathways in RF plants included many biosynthetic pathways of secondary metabolism, carbohydrate metabolism, and energy metabolism. In leaves of SF plants, only a few pathways were significantly enriched $(\mathrm{N}$ and $\mathrm{C}$ metabolism) and none were depleted.

A deeper insight into the actual gene expression levels can be provided by determining the DEG compared with the respective controls (Fig. 5; Supplementary Table S3). From the contigs related to the defense system against herbivory (Fig. 5), in leaves of microcuttings in RF subjected to L. dispar, two upregulated chitinase contigs were identified, as well as four peroxidase and laccase contigs (thaumatin and pathogenesisrelated protein 1 and 10 contigs). In contrast, three catalase contigs were downregulated. In RF plants treated with $P$. croceum, chitinase $I V$ and serine endopeptidase inhibitor contigs were downregulated and three laccase contigs upregulated; however, the plants subjected to $P$. croceum did not show differential expression of these contigs. In the source leaves at RF subjected to $P$. croceum and $L$. dispar, two up- and 
downregulated thaumatin, a downregulated endopeptidase inhibitor, and three upregulated laccase contigs were detected. In leaves of SF plants subjected to herbivory, transcripts of two thaumatin and a chitinase contig were much more abundant than in the untreated plants but the $P$. croceum-treated plants showed no significant differences. Also, in sink leaves with cotreatment, thaumatin, chitinase, and subtilisin inhibitor contigs were upregulated. Contigs encoding phenylalanine ammonia or tyrosine alanine ammonia lyase or lipoxygenase were stably expressed in all interaction types. Encoding an essential component of salicylic acid-dependent signaling, enhanced disease susceptibility contig was upregulated in all interaction types, and $M Y B$ transcription factor at $L$. dispar and cotreatment. Three callose synthase contigs were upregulated in L. dispar and one at cotreatment; however, polygalacturonase and hexose transporter were upregulated in $L$. dispar but downregulated in cotreatment. Some contigs were differentially expressed only upon interaction with $L$. dispar. One contig encoding soluble and two granule-bound starch synthases, as well as three encoding starch branching enzyme, were downregulated in $L$. dispar treatment in source leaves at RF but in none of the other treatments. Only a few secondary metabolite biosynthesis-related contigs were differentially expressed. Putatively related to the production of volatile
Sink leaves

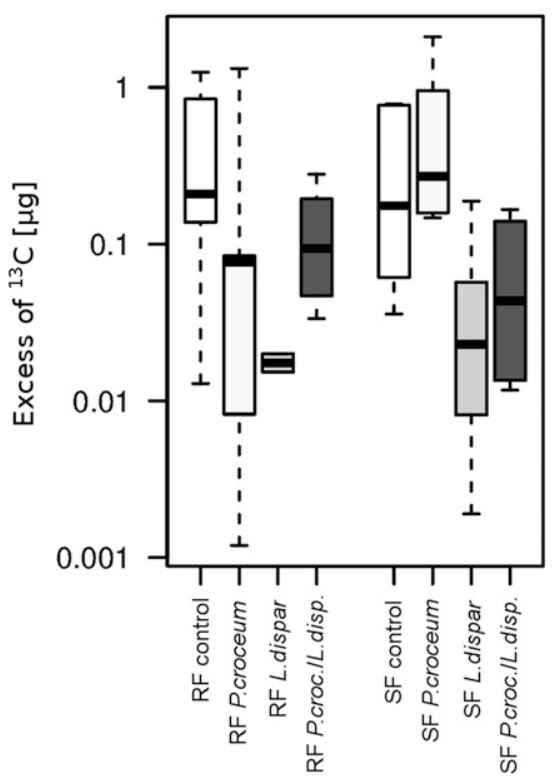

Lateral roots

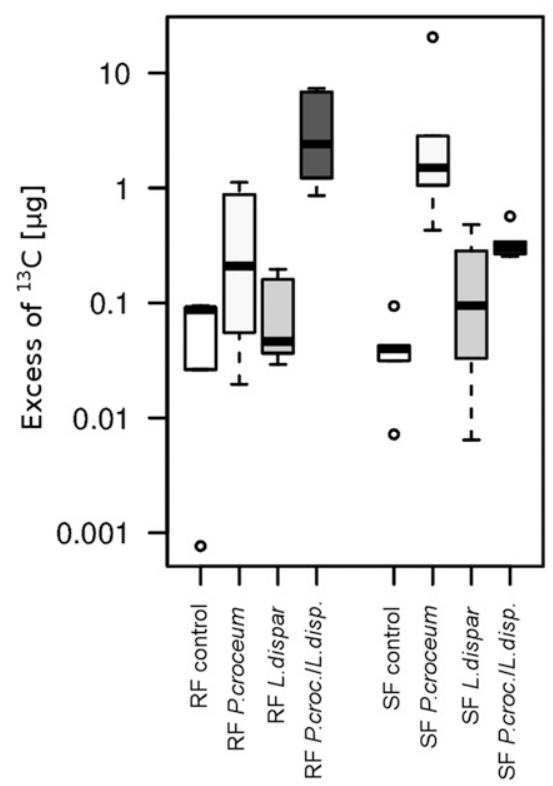

Source leaves

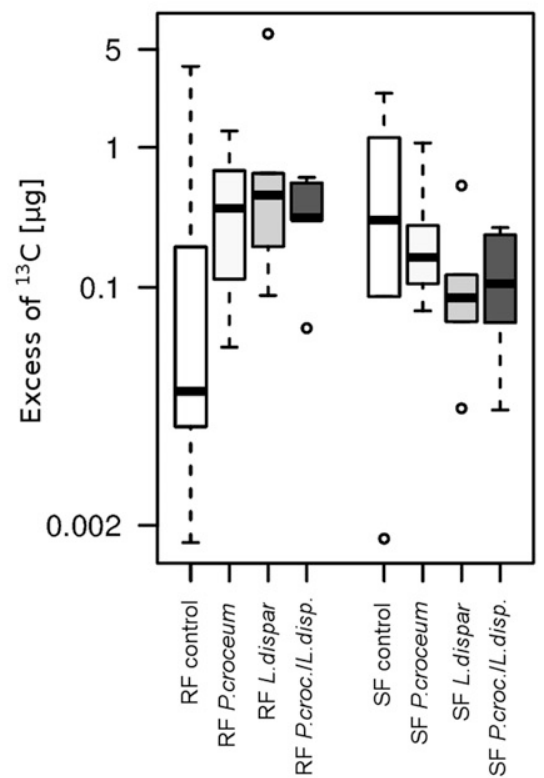

Stem

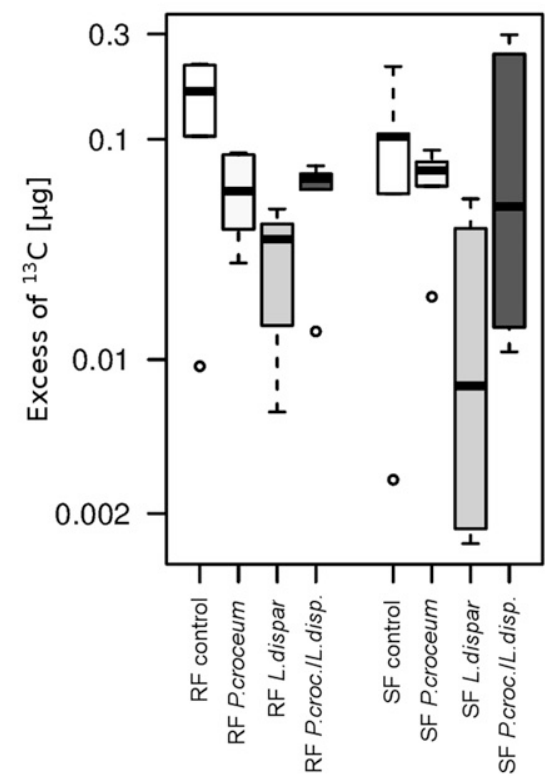

Principal roots

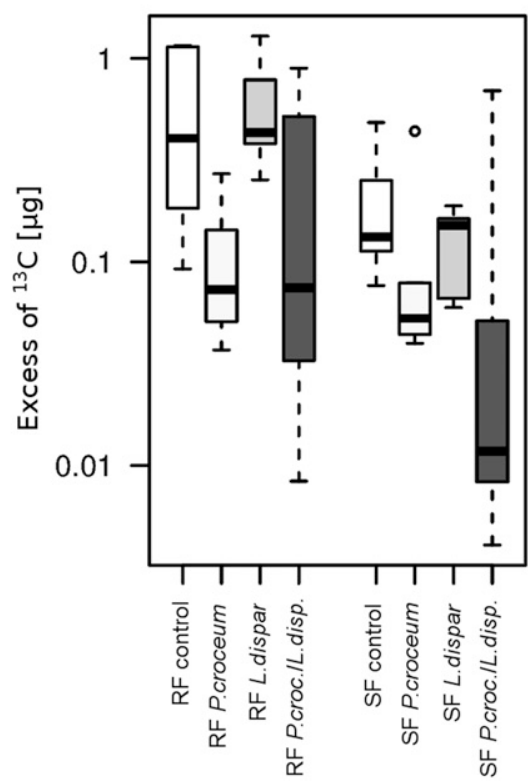

Fig. 1. Effect of inoculation with Piloderma croceum, herbivory by caterpillars of Lymantria dispar, and inoculation with $P$. croceum/L. dispar on the incorporation of ${ }^{13} \mathrm{C}$ into individual plant organs of oak microcuttings in root flush (RF) and shoot flush (SF). Oak microcuttings were inoculated with $P$. croceum (Pilo), fed to larvae of Lymantria dispar (Lym), inoculated with P. croceum and fed to larvae of Lymantria dispar (Pilo/Lym), or not inoculated with the fungus and not fed to the herbivore (control). Bars in the boxplots indicate the upper and lower quartile with median; whiskers indicate minimum and maximum values; dots are outliers. Note that the y-axes are log-transformed. 
organic compounds (VOC), geranylgeranyl-diphosphate reductase was regulated exclusively by $L$. dispar and germacrene-D synthase was downregulated by $L$. dispar but upregulated in cotreatment in source leaves at RF. From phenylpropanoid biosynthesis-related contigs, three caffeoylCoA 3-O-methyltransferase transcripts were upregulated by L. dispar in RF and one in SF.

\section{DISCUSSION}

The results of our multitrophic experiments with an endogenous rhythmically growing plant show that a specific growth stage, RF, displays a strong defense response during attack by a generalist herbivorous caterpillar. It has been previously shown that, in our study system, morphological (Herrmann et al. 1998), physiological (Herrmann et al. 2004), and genetic effects of inoculation in the premycorrhizal phase mirror the plant responses with a developed mycorrhiza. By avoiding the side effects of the variability of mycorrhization rates between plants and the confounding effects of the developed mycorrhizal structure, inoculated plants in the premycorrhizal stage represent an ideal tool for focusing on the genetic basis of plant responses on mycorrhization. Our results suggest that the developmental stage of the plant is an important factor
Sink leaves

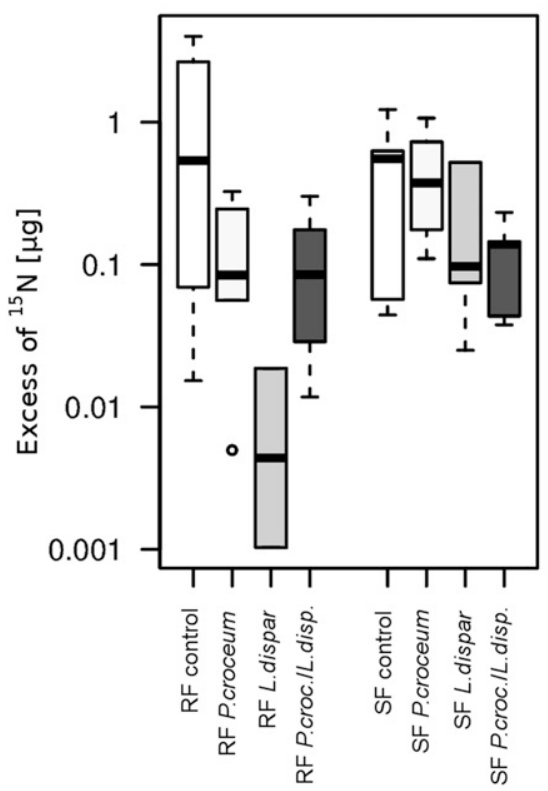

Lateral roots

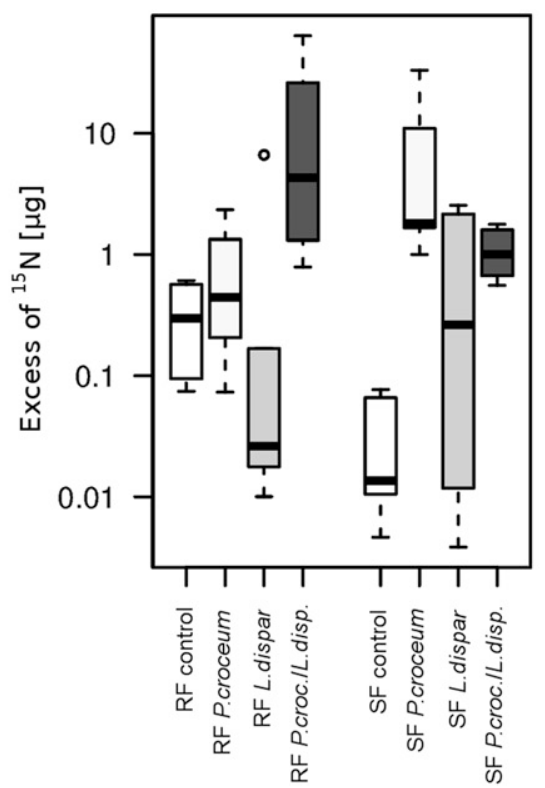

Source leaves

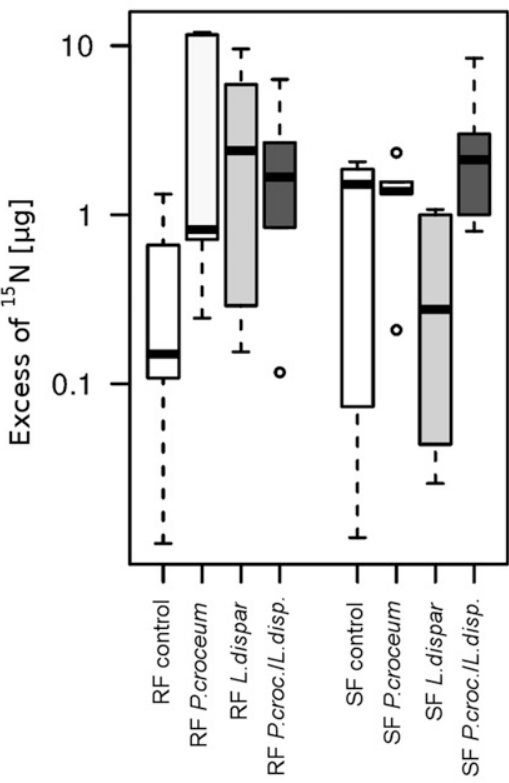

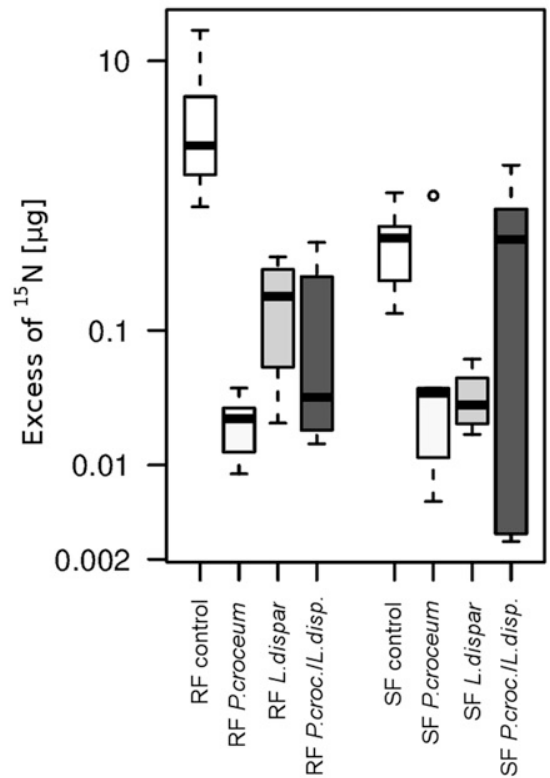

Principal roots

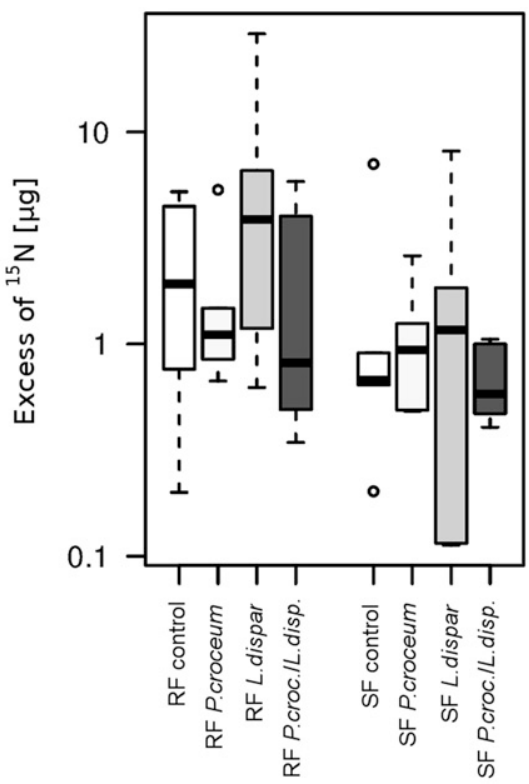

Fig. 2. Effect of inoculation with Piloderma croceum, herbivory by caterpillars of Lymantria dispar, and inoculation with $P$. croceum/L. dispar on the incorporation of ${ }^{15} \mathrm{~N}$ into individual plant organs of oak microcuttings in root flush (RF) and shoot flush (SF). Oak microcuttings were inoculated with $P$. croceum (Pilo), fed to larvae of Lymantria dispar (Lym), inoculated with P. croceum and fed to larvae of Lymantria dispar (Pilo/Lym), or not inoculated with the fungus and not fed to the herbivore (control). Bars in the boxplots indicate the upper and lower quartile with median; whiskers indicate minimum and maximum values. Note that the y-axes are log-transformed. 
influencing the response of rhythmically growing plants to herbivory. In addition, the interaction with mycorrhizal fungi even before mycorrhizas are formed can strongly influence plant defense gene expression responses against herbivory.

\section{Impact on plant biomass and $\mathbf{C}$ and $\mathbf{N}$ incorporation.}

The significant effects of inoculation with $P$. croceum on the biomass of both shoots and roots showed the impact of the fungus during the premycorrhizal phase confirming previous observations by Herrmann et al. (1998). In contrast, the short period of feeding by the herbivore did not significantly affect plant biomass at the levels of sink leaves, source leaves, lateral roots, or principal roots; thus, the effects of the herbivory treatment on genetic and physiological traits must not be interpreted as a consequence of biomass loss. This is in line with the aim of the experiment, to study the consequences of herbivory not as a result of biomass removal but as a trigger for plant responses as affected by inoculation with $P$. croceum. Moreover, plant responses to inoculation with $P$. croceum in terms of biomass changes were not affected by herbivore feeding.

We also found that the allocation of $\mathrm{C}$ and $\mathrm{N}$ was strongly affected by herbivory in a growth-stage-specific way, and that these effects were partly attenuated by the inoculation with the mycorrhizal fungus. Our findings of an enhanced incorporation of $\mathrm{C}$ and $\mathrm{N}$ into growing roots during $\mathrm{RF}$ confirm the allocation shifts related to the ERG described for oak microcuttings DF159 by Herrmann et al. (2015). Babst et al. (2008) reported an increased $\mathrm{C}$ export from leaves of Populus nigra leaves after exposition to $L$. dispar caterpillars. In accordance with this study, we showed that changes in allocation patterns upon herbivory may occur in a few hours after damage even at low levels of herbivory. Such quick responses can be suggested to be important for the plant's ability to tolerate herbivory. Accordingly, our findings show that oak in RF respond to herbivory with a reduced accumulation of carbohydrates into leaves. According to transcriptional changes (see below) and
${ }^{13} \mathrm{C}$-excess data, this effect is attenuated or even reversed in Piloderma croceum-inoculated oak.

\section{Effects on gene expression patterns.}

In our study system, changes in gene expression patterns in oak leaves in response to herbivory were prominent only in source leaves during RF but not in the sink leaves during SF. Our results indicate that oak trees use different strategies against leaf herbivory depending not only on ectomycorrhizal interaction even during the premycorrhizal phase but also on the developmental stage of the tree. The lower number of differently regulated pathways in leaves of oak in SF compared with RF underlines the strong impact of growth stage and the resulting differences in responses to herbivore attack, confirming our first hypothesis. We are also aware that the feeding pattern may explain these differences to a certain degree. Because caterpillars preferred feeding on source leaves, weak transcriptional changes in the sink leaves of SF seem to be plausible. However, systemic defense responses are common in trees (Eyles et al. 2010) and have also been repeatedly demonstrated for oak in response to feeding by Lymantria spp. (Roden and Mattson 2008; Rossiter et al. 1988; Schultz and Baldwin 1982). Faeth (1992) showed that leaf tissue removal increased the level of allelochemicals in the regrowing new foliage. Also, transcriptional changes in trees following herbivory have been shown to be systemic (Babst et al. 2009) and may be even faster and stronger in sink then source leaves (Philippe et al. 2010). Therefore, it is rather unlikely that the very weak response during the SF can be related to the feeding pattern. In accordance with our results, the stage in which roots are not growing $(\mathrm{SF})$ has been found to be also accompanied by stronger changes in gene expression patterns in response to root-associated biota such as the mycorrhiza helper bacterium Streptomyces sp. AcH 505 (Kurth et al. 2015) and the plantparasitic nematode Pratylenchus penetrans (Maboreke et al. 2016). Both growth and defense responses involve strong differences in plant gene expression patterns and physiological
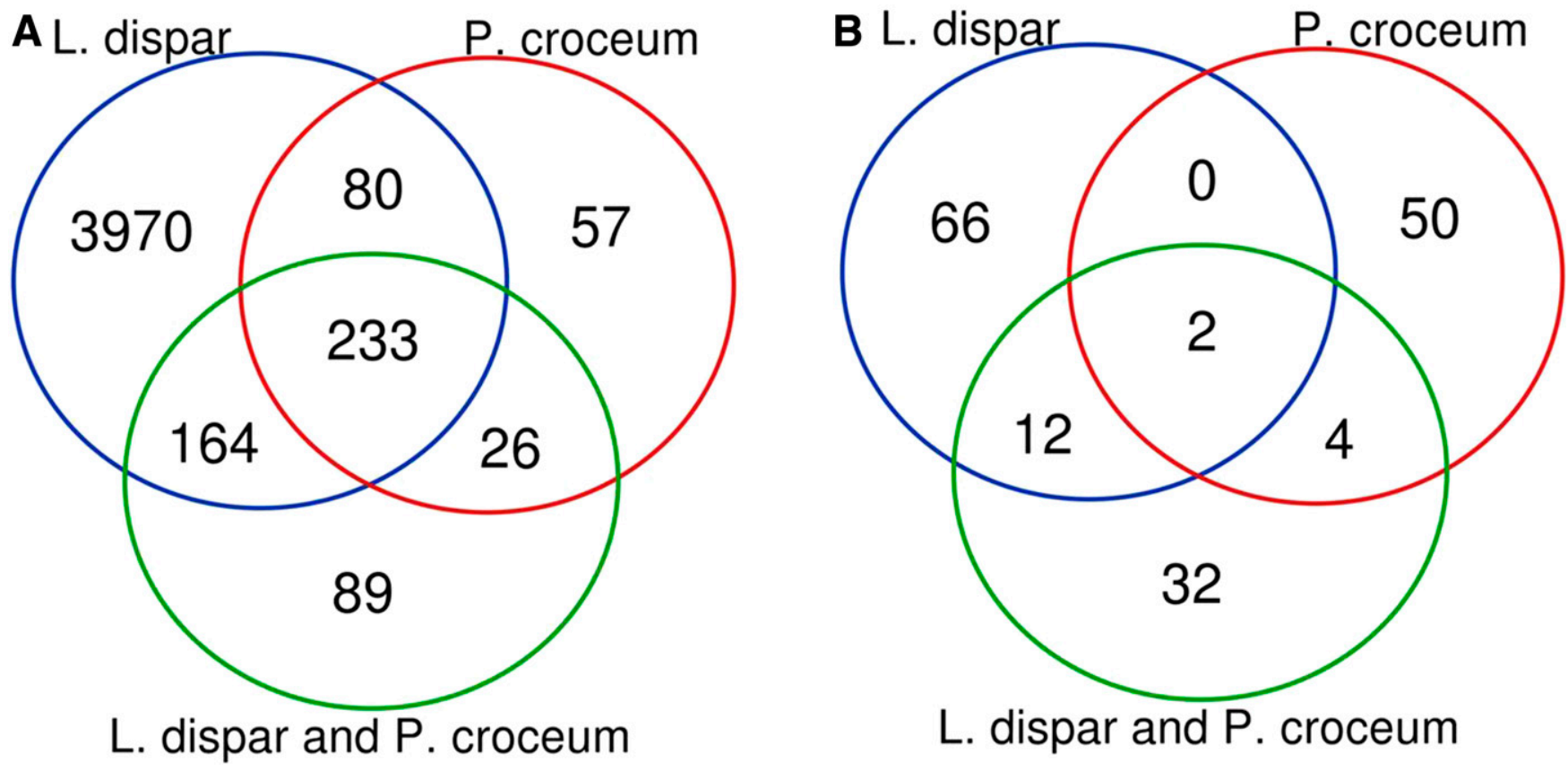

Fig. 3. Venn diagrams of contigs representing differentially expressed genes in leaves of oak microcuttings in $\mathbf{A}$, source leaves during root flush (RF) and $\mathbf{B}$, sink leaves during shoot flush (SF) compared with the control microcuttings. Differential expression was calculated for source leaves in RF and sink leaves in SF by pairwise comparisons of treatments: control versus inoculation with Piloderma croceum, control versus herbivory by Lymantria dispar, and control versus inoculation with $P$. croceum and herbivory by $L$. dispar. Significance was tested using false discovery rate $P<0.01$. 
processes and, due to metabolic costs, growth-defense tradeoffs exist (Karasov et al. 2017). One important way that plants mitigate such costs is by inducible defense gene expression, and our data indicate that, in oak, this is achieved even more precisely, through strong inducible expression of defense genes at the site of interaction in the rest phase only.

Like chemical defense, compensatory growth of plants is a common but costly direct response to herbivory (Haukioja and
Koricheva 2000; McNaughton 1983; Stowe et al. 2000). We could show that many GO terms and pathways related to growth, DNA replication, and starch biosynthesis were enriched in leaves of plants in RF only upon induction by herbivory alone whereas these responses to herbivory were weaker for plants subjected to inoculation with Piloderma croceum. Furthermore, our RNA-Seq data suggest that, during $\mathrm{RF}$ (when leaf development otherwise rests), herbivory leads to

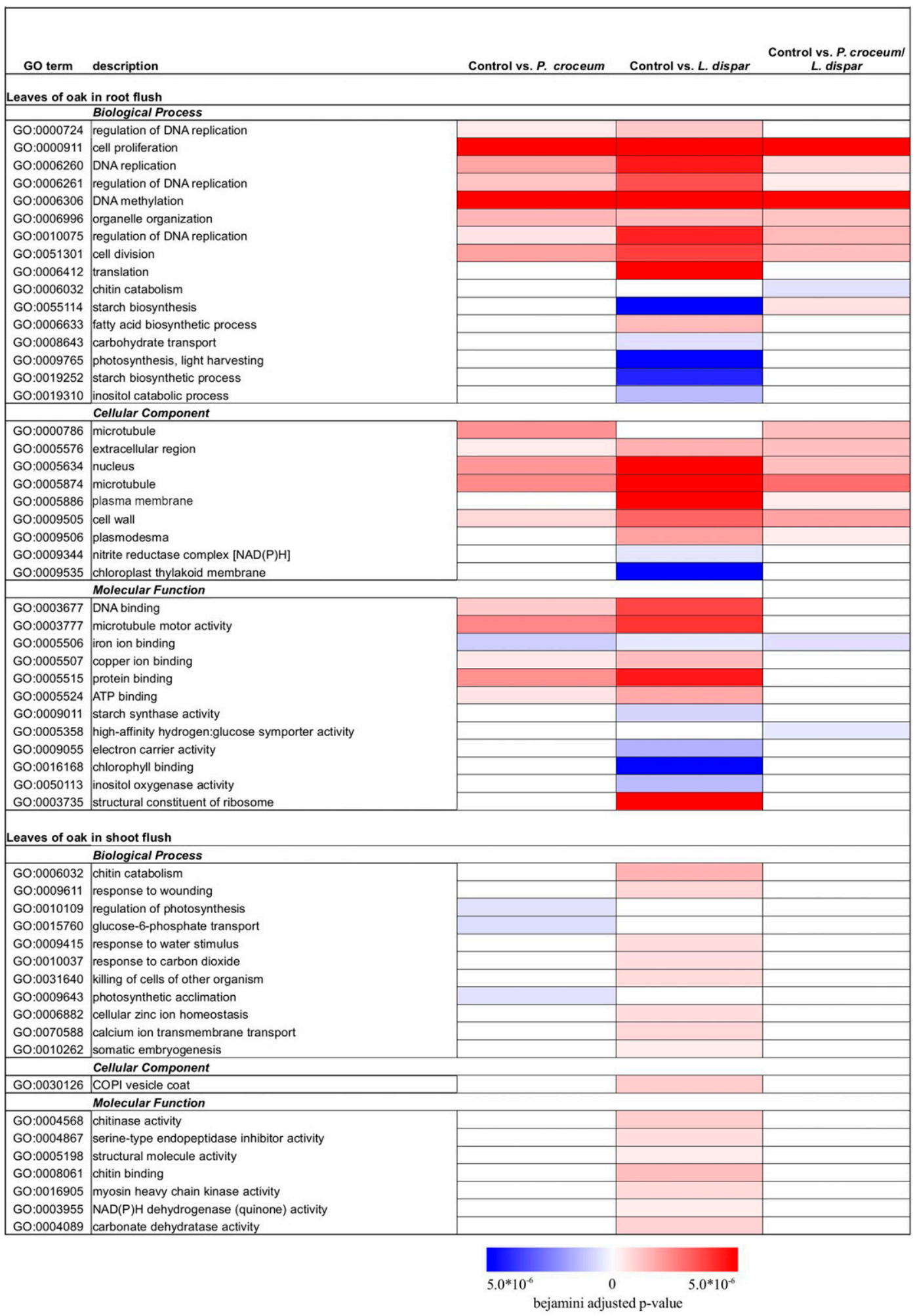

Fig. 4. Heatmap of gene ontology (GO) term enrichment analysis for leaves of oak in root flush and shoot flush. Colors represent the $P$ value adjusted by the Benjamini-Hochberg procedure for the term enrichment, with green representing enrichment and red representing depletion of the corresponding GO terms. 
the activation of leaf molecular machinery for cell division and expansion. Again, this reaction is alleviated in the presence of the mycorrhizal fungus, suggesting that fungal carbohydrate drain might direct the resources to the roots. Similarly, we found an upregulation of genes responsible for the production of protease inhibitors and peroxidases which act as effective antinutrients (Howe and Jander 2008) only in plants with herbivores alone. In the herbivory treatment with $L$. dispar, we found a gene encoding hexose transporter upregulated and genes related to starch synthesis downregulated compared with the control. Furthermore, terpene synthesis-related geranylgeranyl-diphosphate reductase and tannin productionrelated caffeoyl-CoA 3-O-methyltransferase genes were induced upon $L$. dispar treatment.

These genes are known to play a role for plants upon stress (Kiyosue et al. 1998; Seki et al. 2002) and their regulation patterns may indicate the need of saving valuable $\mathrm{C}$ resources from herbivory (Babst et al. 2009; Ferrieri et al. 2013), and reconfiguration of primary and secondary metabolism due to herbivory (Schwachtje and Baldwin 2008).

GO terms of growth, metabolism, and direct defense (e.g., chitin catabolism and response to wounding) were also enriched in leaves of plants in SF subjected to herbivory but no enriched or depleted terms were identified in leaves of plants in SF subjected to both inoculation and herbivory. Our finding of several enriched GO terms related to the cell wall in leaves of oak in RF subjected to herbivory feeding indicates an increasing rigidity in cell walls of plants exposed to herbivory (Onkokesung et al. 2010). Kersten et al. (2013) found a similar pattern for oak as well and interpreted the plant's cell wall as the first barrier in the line of herbivory defense. Moreover, genes encoding pathogenesis-related proteins are also known to be induced by arthropod feeding (Shafique et al. 2014) and were also upregulated in our study only when plants were fed upon by the herbivore.

Similarly, in the study of Kurth et al. (2015), the gene expression response of oak to Streptomyces sp. AcH 505 was also attenuated by the coinoculation with this mycorrhizal fungus. This suggests that $P$. croceum treatment buffers extensive gene expression responses of the oak (Herrmann et al. 2015). Interestingly, in our study, the alleviation of gene expression responses to herbivory by the inoculation with $P$. croceum is comparable with the effect of being in SF. Thus, increased plant vigor which may result from an increased availability of resources caused by either SF or the early phase of symbiosis may redundantize strong responses of the plant to the attack by herbivores.

However, several contigs were also differentially expressed in leaves both exposed to $L$. dispar and in the cotreatment with $P$. croceum. For example, contigs representing genes encoding chitinases were upregulated in leaves of all treatments (herbivore and fungus separately and in combination) compared with the control, which might be explained by the diverse functions of these enzymes, including nonspecific defense reactions which may also occur in response to symbionts (Brunner et al. 1998; Hartl et al. 2012; Kasprzewska 2003; Veluthakkal et al. 2012). Other genes described as related to defense against herbivores and pathogens such as thaumatin like proteins genes (Safavi et al. 2012; Shafique et al. 2014; Wang et al. 2010) have been found to be upregulated in all treatments involving the herbivore regardless of inoculation with $P$. croceum.

Indirect defense of plants often involves the release of VOC triggered by herbivore feeding (Arimura et al. 2004). In tritrophic systems, these compounds might attract natural enemies of the arthropods such as parasites and parasitoids (Havill and Raffa 2000; Kessler and Baldwin 2001; Mondor and Roland 1997, 1998), which are known to efficiently control populations of herbivorous insects such as L. dispar (Alalouni et al. 2013). Terpene synthase and nerolidol synthase are involved in the synthesis of the VOC sesquiterpenes and monoterpenes (Arimura et al. 2004; Baer et al. 2014; Pichersky and Gershenzon 2002). Terpenoid metabolism-related genes

\begin{tabular}{|c|c|c|}
\hline Contig & Log2 FC & Annotation \\
\hline \multicolumn{3}{|c|}{ Control vs. P. croceum Source Leaf RF } \\
\hline comp39593_0_1 & -4.37 & Chitinase IV \\
\hline comp19846_0_1 & 10.29 & Endopept. inhibitor \\
\hline comp41268_0_2 & 8.05 & Laccase 15 \\
\hline comp43452_1_1 & 4.83 & Laccase 14 \\
\hline comp38061_0_1 & -2.83 & Laccase 10 \\
\hline \multicolumn{3}{|c|}{ Control vs. L. dispar Source Leaf RF } \\
\hline comp21061_0_1 & 6.6 & PRP 10 \\
\hline comp37808_0_1 & 4.41 & Thaumatin \\
\hline comp40152_0_1 & 1.91 & PRP 1 \\
\hline comp42425_1_11 & 4.48 & Chitinase I \\
\hline comp34683_0_1 & 2.24 & Chitinase I \\
\hline comp43452_0_8 & 8.15 & Laccase 14 \\
\hline comp38061_1_2 & 8.92 & Laccase 15 \\
\hline comp37403_0_1 & 9.37 & Laccase 6 \\
\hline comp41268_0_1 & 6.07 & Laccase 15 \\
\hline comp40997_1_1 & -2.73 & Laccase 3 \\
\hline comp39773_1_1 & -3.93 & Laccase 14 \\
\hline comp32167_0_1 & 8.14 & Peroxidase 53 \\
\hline comp37126_0_2 & 6.94 & Peroxidase \\
\hline comp38831_0_5 & 4.47 & Peroxidase 37 \\
\hline comp30270_1_1 & 4.16 & Peroxidase \\
\hline comp29279_1_1 & 2.65 & Peroxidase 31 \\
\hline comp43534_1_1 & -2.81 & Peroxidase 5 \\
\hline comp40472_0_1 & -4.34 & Peroxidase 5 \\
\hline comp42954_1_26 & -7.03 & Peroxidase 48 \\
\hline comp32087_0_2 & -1.21 & Catalase \\
\hline comp32087_0_3 & -8.33 & Catalase 2 \\
\hline comp32087_0_2 & -1.21 & Catalase \\
\hline comp23177_1_1 & -1.7 & Catalase \\
\hline comp32087_0_3 & -8.33 & Catalase \\
\hline comp37985_0_1 & 1.34 & SOD \\
\hline \multicolumn{3}{|c|}{ Control vs. L. dispar Sink Leaf SF } \\
\hline comp36076_0_1 & 9.15 & Thaumatin \\
\hline comp27895_0_1 & 9.1 & Thaumatin \\
\hline comp40096_0_1 & 8.63 & Chitinase IV \\
\hline \multicolumn{3}{|c|}{ Control vs. P. croceum and L. dispar Source Leaf RF } \\
\hline comp43430_0_3 & 5.65 & Thaumatin \\
\hline comp32144_0_1 & 3.08 & Thaumatin \\
\hline comp39324_1_4 & -2.13 & Thaumatin \\
\hline comp27895_0_1 & -3.64 & Thaumatin \\
\hline comp39593_0_2 & -3.75 & Chitinase IV \\
\hline comp19846_0_1 & -3.88 & Endopept. inhibitor \\
\hline comp43452_0_8 & 6.71 & Laccase \\
\hline comp41268_0_3 & 6.09 & Laccase 14 \\
\hline comp38061_0_1 & 5.43 & Laccase \\
\hline \multicolumn{3}{|c|}{ Control vs. P. croceum and L. dispar Sink Leaf SF } \\
\hline comp36076_0_1 & 6.03 & Thaumatin \\
\hline comp40096_0_1 & 5.93 & Chitinase IV \\
\hline comp43013_0_1 & 7.17 & Subtilisin inhibitor \\
\hline
\end{tabular}

Fig. 5. Differentially expressed genes related to herbivory response in leaves of oak. Pairwise comparisons of control versus inoculation with Piloderma croceum, control versus herbivory by Lymantria dispar, and control versus inoculation with $P$. croceum and herbivory by $L$. dispar. Annotations mark sequence descriptions derived from BLAST2GO contig assignment, addressing putative functions. $\mathrm{RF}=$ root flush and $\mathrm{SF}=$ shoot flush. Colors indicate direction in regulation: blue $=$ downregulation and red $=$ upregulation. Significance was tested using false discovery rate (FDR) and set for all contigs shown at FDR $<0.01$. 
represented by contigs were exclusively upregulated in plants subjected to both $P$. croceum and $L$. dispar, which indicates the strong influence of $P$. croceum on the defense strategy of oak. Furthermore, Kaling et al. (2018) reported that feeding damage and oviposition by poplar leaf beetle were reduced by ectomycorrhiza development between Laccaria bicolor in the hybrid poplar Populus $\times$ canescens, and that this was associated with increased production of $\mathrm{N}$-containing compounds, volatile aldoximes, and phenylacetonitrile during herbivory in ectomycorrhizal plants. The production and secretion of inducible compounds clearly warrants further investigation.

\section{Conclusions.}

The results of our study indicate that there are separate and interacting effects of inoculation with an ectomycorrhizal fungus and insect herbivory on gene expression patterns in oak dependent on the developmental stage during the endogenous rhythmic growth. Specifically, herbivory-induced changes in resource allocation and regulation of genes related to growth and defense are stronger during phases of root growth and for plants growing without the mycorrhizal fungus, indicating that additional resource supply or allocation of resources to the site of interaction tone down plant responses. The gene expression patterns of oak facing herbivory suggest a change from direct defense mechanisms and compensatory growth to indirect defense via volatile production during the premycorrhizal phase. Taken together, our results indicate a mediating effect of the fungus, especially during a developmental stage when leaf loss hits hardest because only roots are growing. Interestingly, our results suggest that the symbiosis with mycorrhizal fungi does not only support plants in their ability to respond to herbivory but may also induce a change in defense strategies during the RF. Costs and benefits of different strategies to deal with herbivory in a multitrophic context involving beneficial soil microbiota such as mycorrhizal fungi are worth further investigation.

\section{MATERIALS AND METHODS}

\section{Oak, fungus, and herbivorous insect.}

Our experiment was based on oak microcuttings in a microcosm system (TrophinOak joint experimental platform) (Herrmann et al. 2016). We used genetically identical micropropagated pedunculate oak trees of the clone DF159 (Q. robur L.) to exclude genetic variability as a confounding factor in our analyses (Ruhnke et al. 2006, 2009; Schädler et al. 2010). In contrast to seedlings, the obtained microcuttings showed a typical ERG with alternating RF and SF, and resembled mature trees physiologically (Herrmann and Buscot 2008; Herrmann et al. 1998). These flushes can be clearly identified using morphological traits following Herrmann et al. (1998). Furthermore, microcuttings are small enough to use in experiments in the laboratory under controlled conditions.

The oak clone DF159 was micropropagated and rooted according to Herrmann et al. (1998), then cultivated in soilbased microcosms by placing rooted microcuttings in Petri dishes filled with $\gamma$-sterilized soil, as previously described by Herrmann et al. (2016) and Tarkka et al. (2013). To investigate the effects of a mycorrhizal fungus on a host tree during an early phase of the symbiosis, we used the ectomycorrhizal fungus $P$. croceum Hjortst. strain 729 (DSM-4824). P. croceum is a common ectomycorrhizal fungus of both coniferous and hardwood tree species and an established model for both ecological and physiological studies, as described by Tarkka et al. (2013). In brief, half of the oak microcuttings were inoculated with the fungus at the beginning of the experiment by mixing a substrate mixture of vermiculite and sphagnum peat containing a 2-week-old liquid fungal mixture (1:1 [vol/vol]) with the sterilized soil (Supplementary Fig. S1). For the other half of the microcuttings, soil was mixed with the same but sterile noninoculated substrate mixture.

To test the effect of herbivory, we used larvae of the polyphagous moth Lymantria dispar (Lepidoptera: Noctuidae). Egg masses of the New Jersey lab strain were raised under the same environmental conditions as the oak microcuttings and reared on artificial gypsy moth diet (based on wheat germ). Third-instar larvae were used in the experiments.

\section{Experimental design and $\mathrm{C} / \mathrm{N}$ allocation analysis.}

The Petri dish microcosm experiments were conducted in growth chambers with a photosynthetic photon flux density of $180 \mu \mathrm{mol} \mathrm{m} \mathrm{m}^{-2} \mathrm{~s}^{-1}$, a long-day setting (16 h of light and $8 \mathrm{~h}$ of darkness), a constant temperature of $23^{\circ} \mathrm{C}$, and a relative air humidity of $75 \%$ (Ton et al. 2002). After 4 weeks, $5 \mathrm{ml}$ of sterilized tap water was added to each microcosm with a sterile syringe.

We used a full-factorial experiment consisting of control (oak microcuttings alone), L. dispar (oak microcuttings plus herbivory by $L$. dispar larvae), $P$. croceum (oak microcuttings plus inoculation with $P$. croceum), and combined $L$. dispar/P.croceum (oak microcuttings plus $L$. dispar plus $P$. croceum).

Sixty days after setting up the microcosms, all microcosms were briefly opened under sterile conditions and ${ }^{15} \mathrm{NH}_{4}{ }^{15} \mathrm{NO}_{3}$ ( $5 \mathrm{ml}$ at $0.02 \mathrm{~g} \mathrm{liter}^{-1} ; 98$ atom\% ${ }^{15} \mathrm{~N}$; Sigma) was added to the soil containing roots. One day after the addition of ${ }^{15} \mathrm{~N}$-labeled ammonium nitrate, the "aboveground" parts of each plant chosen for herbivory exposure ( $L$. dispar: $n=12$; L. dispar/P. croceum: $n=15$ ) were exposed to one-third instar larva of $L$. dispar. Each plant was covered with a bag with a mesh size of $100 \mu \mathrm{m}$ to contain the larva. The feeding progress was checked twice an hour, and nonfeeding larvae were exchanged with fresh ones. Larvae were allowed to feed on all leaves. However, they nearly exclusively fed on source leaves and avoided sink leaves. After $6 \mathrm{~h}$, all larvae were removed. Immediately thereafter, all plants were transferred to a labeling chamber. That night, the ambient air $\mathrm{CO}_{2}$ in the labeling chamber was completely exchanged with ${ }^{13} \mathrm{CO}_{2}$ (10 atom\%) in the dark. The $\mathrm{CO}_{2}$ concentration was adjusted to $401 \pm$ $3 \mu 1$ liter $^{-1}$ (mean \pm standard deviation [SD]), yielding 9.2 \pm 0.1 atm $\%{ }^{13} \mathrm{C}$ (mean $\pm \mathrm{SD}$ ). The ${ }^{13} \mathrm{C}$ labeling of the microcuttings took place in the subsequent $16 \mathrm{~h}$, starting with the first light.

Plants were considered according to morphological traits either during the RF stage B (RF; 35) or to the SF stage D (SF; 36), as defined by Herrmann et al. (2015), which form the levels of the factor stage in our analysis (control: RF, $n=15$ and SF, $n=12$; inoculation: RF, $n=8$ and SF, $n=9$; herbivory: RF, $n=6$ and SF, $n=6$; and inoculation/herbivory: RF, $n=6$ and $\mathrm{SF}, n=9)$. The following plant compartments were separated according to Angay et al. (2014): (i) sink leaves (developing leaves that continue to import photoassimilates from source leaves) (i.e., terminal leaves, not yet fully developed or buds), (ii) source leaves (fully developed leaves that export their own products of photosynthesis) (i.e., subterminal leaves), (iii) stems, (iv) principal roots (i.e., main roots originating from stem), and (v) lateral roots (i.e., fine roots originating from principal roots). After determining the fresh weights, all samples were immediately frozen in liquid $\mathrm{N}$ and stored at $-80^{\circ} \mathrm{C}$. Dry weights used in the statistical analyses were calculated using reference values of each plant organ of RF and SF oak clone DF159 microcuttings given by Angay et al. (2014).

For analyses of $\mathrm{C}$ and $\mathrm{N}$ allocation, parts of plant organs of each treatment and control were separately pooled $(n=6$ biological replicates), dried, and ground using a ball mill (Type MM2; Retsch, Hahn, Germany). Stable $\mathrm{C}$ and $\mathrm{N}$ isotopes in the 
ground tissues were quantified using an isotope-ratio mass spectrometry (GVI-Isoprime; Elementar, Hanau, Germany) coupled to an elemental analyzer (EA3000; Euro Vector, Milan, Italy). Repeated measurement of a laboratory working standard gave a precision of $\delta^{13} \mathrm{C}<0.1 \%$ o $\left.\mathrm{SD}, n=10\right) .{ }^{13} \mathrm{C}$ and ${ }^{15} \mathrm{~N}$ excess were calculated per plant compartment and on a wholeplant level over unlabeled microcuttings.

\section{Transcriptomics.}

Despite the drawbacks of GO analysis (Ashburner et al. 2000; Rhee et al. 2008; Young et al. 2010), together with pairwise comparisons of gene expression levels, GO enrichment analysis is a useful method for extracting patterns from masses of transcriptomic data and annotating the oak transcriptome according to the OakContigDF159.1 reference library (Tarkka et al. 2013).

Source and sink leaves of plants during RF and SF, respectively, were used for transcriptomic analysis according to Tarkka et al. (2013). The treatments included control, herbivory by $L$. dispar, inoculation with $P$. croceum, and treatment with $L$. dispar as well as $P$. croceum. First, the plants of each stage of growth and treatment type were shared in three pools. At this stage, each pool, which represents a biological replicate, consisted of at least two plants. The leaves of the pooled plants were used for RNA extraction.

In total, the 24 leaf RNA samples consisted of three biological replicates each of control/RF, control/SF, L. dispar/RF, L. dispar $/ \mathrm{SF}, P$. croceum $/ \mathrm{RF}, P$. croceum $/ \mathrm{SF}, L$. dispar $/ P$. croceum $/ \mathrm{RF}$, and $L$. dispar/P. croceum/SF. Total RNA was extracted using the MasterPure Plant RNA Purification Kit (Epicentre Technologies Corporation, Madison, WI, U.S.A.), according to the manufacturer's protocol, from $50 \mathrm{mg}$ of leaf material. The quality and quantity of RNA were checked using a Nanodrop spectrophotometer (Thermo Scientific) and a Nano Chip and Bioanalyzer 2100 (Agilent). RNA samples were used to produce 100-bp paired-end libraries which were sequenced using an Illumina HiSeq 2000 at the Beijing Genomics Institute, Hong Kong, China. Illumina reads were processed as described by Tarkka et al. (2013). Briefly, poly (A) tails and low-complexity and low-quality sequences were removed with SeqClean. Nucleotides with a quality score $<20$ were removed from the ends of the reads using a custom Java script. Sequences $<50$ bp were discarded, as were sequences without paired-end information after preprocessing.

Gene expression analysis by real-time $q R T-P C R$. The reliability of RNA-Seq analyses derived from microcuttings of oak clone DF159 in controlled trophic interactions with $P$. croceum has been demonstrated earlier by Herrmann et al. (2015), Kurth et al. (2014), and Tarkka et al. (2013). To obtain independent plant material to confirm the RNA-Seq results, we performed a second experiment with an identical experimental setup. According to morphological traits, 28 plants were at RF and 28 plants at SF (control: RF, $n=7$ and SF, $n=7$; inoculated: RF, $n=7$ and SF, $n=7$; herbivory: RF, $n=7$ and SF, $n=7$; and inoculated plus herbivory: RF, $n=7$ and SF, $n=7$ ). After determining the fresh weights, all samples were immediately frozen in liquid $\mathrm{N}$ and stored at $-80^{\circ} \mathrm{C}$. Total RNA from oak source leaves at RF was extracted using the RNeasy Plant Mini Kit (Qiagen), according to the manufacturer's protocol, from $50 \mathrm{mg}$ of leaf material. The total RNA was treated with RNasefree DNase set (Qiagen). The quality and quantity of RNA were checked using a Nanodrop spectrophotometer (Thermo Scientific), and a Nano Chip and Bioanalyzer 2100 (Agilent). Firststrand cDNA was synthesized from $1 \mu \mathrm{g}$ of purified total RNA using the ImProm-II Reverse Transcription System (Promega) according to the manufacturer's instructions. Real-time qRT-PCR was performed using the iQ 5 real-time PCR detection system (Bio-Rad) and the gene-specific primers described in Supplementary Table S5. Amplification conditions were $10 \mathrm{~min}$ at $95^{\circ} \mathrm{C}$ followed by 40 cycles at $95^{\circ} \mathrm{C}$ for $15 \mathrm{~s}$ and $60^{\circ} \mathrm{C}$ for $1 \mathrm{~min}$. The specificity of each PCR amplification procedure was verified by melt-curve analysis of the PCR product with a heat dissociation protocol (from 60 to $95^{\circ} \mathrm{C}$ ). Relative quantification of specific mRNA levels was performed using the comparative method of Livak and Schmittgen (2001). Expression values were normalized using the oak $18 \mathrm{~S}$ ribosomal RNA gene (Tarkka et al. 2013).

\section{Statistical analyses.}

The processed Illumina reads were aligned against the OakContigDF159.1 reference transcriptome (Tarkka et al. 2013) using bowtie (Langmead et al. 2009) and quantified using RSEM (Li and Dewey 2011). The significance of differences in gene expression was measured via pairwise comparisons between contigs of control versus $L$. dispar, control versus $P$. croceum, and control versus $P$. croceum $/ L$. dispar, separately for plants in RF and for plants in SF, using the edgeR function (Robinson et al. 2010) of the Bioconductor package (Gentleman et al. 2004) in R (R Core Group).To ensure that RNA-Seq data are solid, contigs were called to be differentially expressed in a treatment compared with the corresponding control condition when exhibiting a Benjamini-Hochberg adjusted $P<0.01$ after adjustment for multiple testing (Bluthgen et al. 2005; Conesa et al. 2005; Kanehisa et al. 2014). This false discovery rate is strict compared with the usually used level of $P<0.05$. Resulting gene lists were analyzed for enriched GO terms and KEGG pathways using the Bioconductor package GOseq (Langmead et al. 2009). Biomass and C/N allocation were statistically analyzed in $\mathrm{R}$ using the $\mathrm{lm}$ function, implementing a three-way ANOVA. ${ }^{13} \mathrm{C}$ and ${ }^{15} n$ values were $\log _{10}$-transformed prior analyses to achieve normal distribution of residuals.

\section{ACKNOWLEDGMENTS}

We thank the TrophinOak Platform of the Helmholtz Centre for Environmental Research (UFZ, Halle, Germany), especially I. Krieg, B. Krause, and $\mathrm{K}$. Hommel, for providing oak microcutting microcosms inoculated with P. croceum; D. Goertz (IFFF, Wien, Austria) for providing egg masses of Lymantria dispar; C. Seidler (TUM, Weihenstephan, Germany) for setting up the mobile C-labeling chamber; and A. Schmidt, M. Graf, and U. Alalouni for support during the harvesting.

\section{LITERATURE CITED}

Alalouni, U., Schädler, M., and Brandl, R. 2013. Natural enemies and environmental factors affecting the population dynamics of the gypsy moth. J. Appl. Entomol. 137:721-738.

Angay, O., Fleischmann, F., Recht, S., Herrmann, S., Matyssek, R., Oßwald, W., Buscot, F., and Grams, T. E. E. 2014. Sweets for the foe-Effects of nonstructural carbohydrates on the susceptibility of Quercus robur against Phytophthora quercina. New Phytol. 203:1282-1290.

Arimura, G., Huber, D. P. W., and Bohlmann, J. 2004. Forest tent caterpillars (Malacosoma disstria) induce local and systemic diurnal emissions of terpenoid volatiles in hybrid poplar (Populus trichocarpa $\times$ deltoides): cDNA cloning, functional characterization, and patterns of gene expression of (-)-germacrene D synthase, PtdTPS1. Plant J. 37:603-616.

Ashburner, M., Ball, C. A., Blake, J. A., Botstein, D., Butler, H., Cherry, J. M., Davis, A. P., Dolinski, K., Dwight, S. S., Eppig, J. T., Harris, M. A., Hill, D. P., Issel-Tarver, L., Kasarskis, A., Lewis, S., Matese, J. C., Richardson, J. E., Ringwald, M., Rubin, G. M., and Sherlock, G.; The Gene Ontology Consortium. 2000. Gene ontology: Tool for the unification of biology. Nat. Genet. 25:25-29.

Baar, J., Horton, T. R., Kretzer, A. M., and Bruns, T. D. 1999. Mycorrhizal colonization of Pinus muricata from resistant propagules after a standreplacing wildfire. New Phytol. 143:409-418.

Babst, B. A., Ferrieri, R. A., Thorpe, M. R., and Orians, C. M. 2008. Lymantria dispar herbivory induces rapid changes in carbon transport and partitioning in Populus nigra. Entomol. Exp. Appl. 128:117-125. 
Babst, B. A., Sjödin, A., Jansson, S., and Orians, C. M. 2009. Local and systemic transcriptome responses to herbivory and jasmonic acid in Populus. Tree Genet. Genomes 5:459-474.

Baer, P., Rabe, P., Citron, C. A., de Oliveira Mann, C. C., Kaufmann, N., Groll, M., and Dickschat, J. S. 2014. Hedycaryol synthase in complex with nerolidol reveals terpene cyclase mechanism. ChemBioChem 15: 213-216.

Baldwin, I. T., Halitschke, R., Kessler, A., and Schittko, U. 2001. Merging molecular and ecological approaches in plant-insect interactions. Curr. Opin. Plant Biol. 4:351-358.

Bi, H. H., Song, Y. Y., and Zeng, R. S. 2007. Biochemical and molecular responses of host plants to mycorrhizal infection and their roles in plant defense. Allelopathy J. 20:15-27.

Bluthgen, N., Brand, K., Cajavec, B., Swat, M., Herzel, H., and Beule, D. 2005. Biological profiling of gene groups utilizing Gene Ontology. Pages 106-115 in: Genome Inf. Int. Conf. Genome Inf. 16.

Borowicz, V. A. 1997. A fungal root symbiont modifies plant resistance to an insect herbivore. Oecologia 112:534-542.

Brändle, M., and Brandl, R. 2001. Species richness of insects and mites on trees: Expanding Southwood. J. Anim. Ecol. 70:491-504.

Brunner, F., Stintzi, A., Fritig, B., and Legrand, M. 1998. Substrate specificities of tobacco chitinases. Plant J. 14:225-234.

Conesa, A., Götz, S., García-Gómez, J. M., Terol, J., Talón, M., and Robles, M. 2005. Blast2GO: A universal tool for annotation, visualization and analysis in functional genomics research. Bioinformatics 21:3674-3676.

Crawley, M. J. 1996. Plant-herbivore dynamics. Pages 401-474 in: Plant Ecology. M. J. Crawley, ed. Blackwell Publishing Ltd, Oxford.

Eyles, A., Bonello, P., Ganley, R., and Mohammed, C. 2010. Induced resistance to pests and pathogens in trees. New Phytol. 185:893-908.

Faeth, S. H. 1992. Do defoliation and subsequent phytochemical responses reduce future herbivory on oak trees? J. Chem. Ecol. 18:915-925.

Felten, J., Kohler, A., Morin, E., Bhalerao, R. P., Palme, K., Martin, F., Ditengou, F. A., and Legué, V. 2009. The ectomycorrhizal fungus Laccaria bicolor stimulates lateral root formation in poplar and Arabidopsis through auxin transport and signaling. Plant Physiol. 151: 1991-2005.

Ferrieri, A. P., Agtuca, B., Appel, H. M., Ferrieri, R. A., and Schultz, J. C. 2013. Temporal changes in allocation and partitioning of new carbon as (11)C elicited by simulated herbivory suggest that roots shape aboveground responses in Arabidopsis. Plant Physiol. 161:692-704.

Frettinger, P., Derory, J., Herrmann, S., Plomion, C., Lapeyrie, F., Oelmüller, R., Martin, F., and Buscot, F. 2007. Transcriptional changes in two types of pre-mycorrhizal roots and in ectomycorrhizas of oak microcuttings inoculated with Piloderma croceum. Planta 225:331-340.

Fritz, M., Jakobsen, I., Lyngkjær, M. F., Thordal-Christensen, H., and PonsKühnemann, J. 2006. Arbuscular mycorrhiza reduces susceptibility of tomato to Alternaria solani. Mycorrhiza 16:413-419.

Frost, C. J., and Hunter, M. D. 2008. Herbivore-induced shifts in carbon and nitrogen allocation in red oak seedlings. New Phytol. 178:835-845.

Gange, A. C., and West, H. M. 1994. Interactions between arbuscular mycorrhizal fungi and foliar-feeding insects in Plantago lanceolata L. New Phytol. 128:79-87.

Gehring, C. A., and Whitham, T. G. 1994. Interactions between aboveground herbivores and the mycorrhizal mutualists of plants. Trends Ecol. Evol. 9:251-255.

Gentleman, R. C., Carey, V. J., Bates, D. M., Bolstad, B., Dettling, M., Dudoit, S., Ellis, B., Gautier, L., Ge, Y., Gentry, J., Hornik, K., Hothorn, T., Huber, W., Iacus, S., Irizarry, R., Leisch, F., Li, C., Maechler, M., Rossini, A. J., Sawitzki, G., Smith, C., Smyth, G., Tierney, L., Yang, J. Y. H., and Zhang, J. 2004. Bioconductor: Open software development for computational biology and bioinformatics. Genome Biol. 5:R80.

Halldórsson, G., Sverrisson, H., Eyjólfsdóttir, G. G., and Oddsdóttir, E. S. 2000. Ectomycorrhizae reduce damage to Russian larch by Otiorhyncus larvae. Scand. J. For. Res. 15:354-358.

Harmer, R. 1990. Relation of shoot growth phases in seedling oak to development of the tap root, lateral roots and fine root tips. New Phytol. 115:23-27.

Hartl, L., Zach, S., and Seidl-Seiboth, V. 2012. Fungal chitinases: Diversity, mechanistic properties and biotechnological potential. Appl. Microbiol. Biotechnol. 93:533-543.

Haukioja, E., and Koricheva, J. 2000. Tolerance to herbivory in woody vs. herbaceous plants. Evol. Ecol. 14:551-562

Havill, N. P., and Raffa, K. F. 2000. Compound effects of induced plant responses on insect herbivores and parasitoids: Implications for tritrophic interactions. Ecol. Entomol. 25:171-179.

Hermsmeier, D., Schittko, U., and Baldwin, I. T. 2001. Molecular interactions between the specialist herbivore Manduca sexta (Lepidoptera, Sphingidae) and its natural host Nicotiana attenuata. I. Large-scale changes in the accumulation of growth- and defense-related plant mRNAs. Plant Physiol. 125:683-700.

Herrmann, S., and Buscot, F. 2007. Cross talks at the morphogenetic, physiological and gene regulation levels between the mycobiont Piloderma croceum and oak microcuttings (Quercus robur) during formation of ectomycorrhizas. Phytochemistry 68:52-67.

Herrmann, S., and Buscot, F. 2008. Why and how using micropropagated trees rather than germinations for controlled synthesis of ectomycorrhizal associations? Pages 439-465 in: Mycorrhiza. A. Varma, ed. Springer, Berlin, Heidelberg, Germany.

Herrmann, S., Grams, T. E. E., Tarkka, M. T., Angay, O., Bacht, M., Bönn, M., Feldhahn, L., Graf, M., Kurth, F., Maboreke, H., Mailander, S. Recht, S., Fleischmann, F., Ruess, L., Schädler, M., Scheu, S., Schrey, S., and Buscot, F. 2016. Endogenous rhythmic growth, a trait suitable for the study of interplays between multitrophic interactions and tree development. Perspect. Plant Ecol. Evol. Syst. 19:40-48.

Herrmann, S., Munch, J. C., and Buscot, F. 1998. A gnotobiotic culture system with oak microcuttings to study specific effects of mycobionts on plan morphology before, and in the early phase of, ectomycorrhiza formation by Paxillus involutus and Piloderma croceum. New Phytol. 138:203-212.

Herrmann, S., Oelmüller, R., and Buscot, F. 2004. Manipulation of the onset of ectomycorrhiza formation by indole-3-acetic acid, activated charcoal or relative humidity in the association between oak microcuttings and Piloderma croceum: Influence on plant development and photosynthesis. J. Plant Physiol. 161:509-517.

Herrmann, S., Recht, S., Boenn, M., Feldhahn, L., Angay, O., Fleischmann, F., Tarkka, M. T., Grams, T. E. E., and Buscot, F. 2015. Endogenous rhythmic growth in oak trees is regulated by internal clocks rather than resource availability. J. Exp. Bot. 66:7113-7127.

Howe, G. A., and Jander, G. 2008. Plant immunity to insect herbivores. Annu. Rev. Plant Biol. 59:41-66.

Hui, D., Iqbal, J., Lehmann, K., Gase, K., Saluz, H. P., and Baldwin, I. T. 2003. Molecular interactions between the specialist herbivore Manduca sexta (Lepidoptera, Sphingidae) and its natural host Nicotiana attenuata: V. Microarray analysis and further characterization of large-scale changes in herbivore-induced mRNAs. Plant Physiol. 131:1877-1893.

Jones, C. G., and Last, F. T. 1991. Ectomycorrhizae and trees: Implications for aboveground herbivory. Pages 65-103 in: Microbial Mediation of Plant-Herbivore Interactions. P. Barbosa, V. A. Krischik, and C. G. Jones, eds. John Wiley \& Sons, Chichester, NY, U.S.A.

Kaling, M., Schmidt, A., Moritz, F., Rosenkranz, M., Witting, M., Kasper, K., Janz, D., Schmitt-Kopplin, P., Schnitzler, J. P., and Polle, A. 2018 Mycorrhiza-triggered transcriptomic and metabolomic networks impinge on herbivore fitness. Plant Physiol. 176:2639-2656.

Kanehisa, M., Goto, S., Sato, Y., Kawashima, M., Furumichi, M., and Tanabe, M. 2014. Data, information, knowledge and principle: Back to metabolism in KEGG. Nucleic Acids Res. 42 (D1):D199-D205.

Karasov, T. L., Chae, E., Herman, J. J., and Bergelson, J. 2017. Mechanisms to mitigate the tradeoffs between growth and defense. Plant Cell 29: 666-680.

Kasprzewska, A. 2003. Plant chitinases-Regulation and function. Cell. Mol. Biol. Lett. 8:809-824.

Kempel, A., Schmidt, A. K., Brandl, R., and Schädler, M. 2010. Support from the underground: Induced plant resistance depends on arbuscular mycorrhizal fungi. Funct. Ecol. 24:293-300.

Kersten, B., Ghirardo, A., Schnitzler, J.-P., Kanawati, B., Schmitt-Kopplin, P., Fladung, M., and Schroeder, H. 2013. Integrated transcriptomics and metabolomics decipher differences in the resistance of pedunculate oak to the herbivore Tortrix viridana L. BMC Genomics 14:737.

Kessler, A., and Baldwin, I. T. 2001. Defensive function of herbivoreinduced plant volatile emissions in nature. Science 291:2141-2144.

Kiyosue, T., Abe, H., Yamaguchi-Shinozaki, K., and Shinozaki, K. 1998. ERD6, a cDNA clone for an early dehydration-induced gene of Arabidopsis, encodes a putative sugar transporter. Biochim. Biophys. Acta 1370:187-191.

Kõljalg, U., Dahlberg, A., Taylor, A. F. S., Larsson, E., Hallenberg, N., Stenlid, J., Larsson, K.-H., Fransson, P. M., Kårén, O., and Jonsson, L. 2000 Diversity and abundance of resupinate thelephoroid fungi as ectomycorrhizal symbionts in Swedish boreal forests. Mol. Ecol. 9:1985-1996.

Kurth, F., Feldhahn, L., Bönn, M., Herrmann, S., Buscot, F., and Tarkka, M. T. 2015. Large scale transcriptome analysis reveals interplay between development of forest trees and a beneficial mycorrhiza helper bacterium. BMC Genomics 16:658.

Kurth, F., Mailänder, S., Bönn, M., Feldhahn, L., Herrmann, S., Große, I., Buscot, F., Schrey, S. D., and Tarkka, M. T. 2014. Streptomyces-induced resistance against oak powdery mildew involves host plant responses in defense, photosynthesis, and secondary metabolism pathways. Mol. Plant-Microbe Interact. 27:891-900. 
Langmead, B., Trapnell, C., Pop, M., and Salzberg, S. L. 2009. Ultrafast and memory-efficient alignment of short DNA sequences to the human genome. Genome Biol. 10:R25.

Li, B., and Dewey, C. N. 2011. RSEM: Accurate transcript quantification from RNA-Seq data with or without a reference genome. BMC Bioinf. 12:323.

Liu, J., Maldonado-Mendoza, I., Lopez-Meyer, M., Cheung, F., Town, C. D., and Harrison, M. J. 2007. Arbuscular mycorrhizal symbiosis is accompanied by local and systemic alterations in gene expression and an increase in disease resistance in the shoots. Plant J. 50:529-544.

Livak, K. J., and Schmittgen, T. D. 2001. Analysis of relative gene expression data using real-time quantitative PCR and $2^{-\Delta \Delta \mathrm{Ct}}$ method. Methods 25:402-408.

Maboreke, H. R., Feldhahn, L., Bönn, M., Tarkka, M. T., Buscot, F., Herrmann, S., Menzel, R., and Ruess, L. 2016. Transcriptome analysis in oak uncovers a strong impact of endogenous rhythmic growth on the interaction with plant-parasitic nematodes. BMC Genomics 17:627.

McNaughton, S. J. 1983. Compensatory plant growth as a response to herbivory. Oikos 40:329-336.

Mondor, E. B., and Roland, J. 1997. Host locating behaviour of Leschenaultia exul and Patelloa pachypyga: Two tachinid parasitoids of the forest tent caterpillar, Malacosoma disstria. Entomol. Exp. Appl. 85:161-168.

Mondor, E. B., and Roland, J. 1998. Host searching and oviposition by Leschenaultia exul, a tachinid parasitoid of the forest tent caterpillar, Malacosoma disstria. J. Insect Behav. 11:583-592.

Onkokesung, N., Gális, I., von Dahl, C. C., Matsuoka, K., Saluz, H.-P., and Baldwin, I. T. 2010. Jasmonic acid and ethylene modulate local responses to wounding and simulated herbivory in Nicotiana attenuata leaves. Plant Physiol. 153:785-798.

Philippe, R. N., Ralph, S. G., Mansfield, S. D., and Bohlmann, J. 2010. Transcriptome profiles of hybrid poplar (Populus trichocarpa $\times$ deltoides) reveal rapid changes in undamaged, systemic sink leaves after simulated feeding by forest tent caterpillar (Malacosoma disstria). New Phytol. 188:787-802.

Pichersky, E., and Gershenzon, J. 2002. The formation and function of plant volatiles: Perfumes for pollinator attraction and defense. Curr. Opin. Plant Biol. 5:237-243.

Pozo, M. J., and Azcón-Aguilar, C. 2007. Unraveling mycorrhiza-induced resistance. Curr. Opin. Plant Biol. 10:393-398.

Read, D. J., Leake, J. R., and Perez-Moreno, J. 2004. Mycorrhizal fungi as drivers of ecosystem processes in heathland and boreal forest biomes. Can. J. Bot. 82:1243-1263.

Rhee, S. Y., Wood, V., Dolinski, K., and Draghici, S. 2008. Use and misuse of the gene ontology annotations. Nat. Rev. Genet. 9:509-515.

Robinson, M. D., McCarthy, D. J., and Smyth, G. K. 2010. edgeR: A Bioconductor package for differential expression analysis of digital gene expression data. Bioinformatics 26:139-140.

Roda, A. L., and Baldwin, I. T. 2003. Molecular technology reveals how the induced direct defenses of plants work. Basic Appl. Ecol. 4:15-26.

Roden, D. B., and Mattson, W. J. 2008. Rapid induced resistance and host species effects on gypsy moth, Lymantria dispar (L.): Implications for outbreaks on three tree species in the boreal forest. For. Ecol. Manage. 255:1868-1873

Rossiter, M. C., Schultz, J. C., and Baldwin, T. T. 1988. Relationships among defoliation, red oaks phenolics, and gypsy moth growth and reproduction. Ecology 69:267-277.

Ruhnke, H., Schädler, M., Klotz, S., Matthies, D., and Brandl, R. 2009. Variability in leaf traits, insect herbivory and herbivore performance within and among individuals of four broad-leaved tree species. Basic Appl. Ecol. 10:726-736.

Ruhnke, H., Schädler, M., Matthies, D., Klotz, S., and Brandl, R. 2006. Are sawflies adapted to individual host trees? A test of the adaptive deme formation hypothesis. Evol. Ecol. Res. 8:1039-1048.

Safavi, K., Zareie, R., and Tabatabaei, B. E. S. 2012. Constitutive expression of thaumatin-like protein (TLP-3) in transgenic tobacco plants leads to enhance resistance to Alternaria alternata. Arch. Phytopathol. Plant Prot. 45:161-169.

Schädler, M., and Ballhorn, D. J. 2017. Beneficial soil microbiota as mediators of the plant defensive phenotype and aboveground plantherbivore interactions. Prog. Bot. 78:305-343.

Schädler, M., Brandl, R., and Kempel, A. 2010. Host plant genotype determines bottom-up effects in an aphid-parasitoid-predator system. Entomol. Exp. Appl. 135:162-169.
Schädler, M., Jung, G., Brandl, R., and Auge, H. 2004. Secondary succession is influenced by belowground insect herbivory on a productive site. Oecologia 138:242-252.

Schenk, P. M., McGrath, K. C., Lorito, M., and Pieterse, C. M. J. 2008. Plant-microbe and plant-insect interactions meet common grounds. New Phytol. 179:251-256.

Schmidt, D. D., Voelckel, C., Hartl, M., Schmidt, S., and Baldwin, I. T. 2005. Specificity in ecological interactions: Attack from the same lepidopteran herbivore results in species-specific transcriptional responses in two solanaceous host plants. Plant Physiol. 138:1763-1773.

Schultz, J. C., Appel, H. M., Ferrieri, A. P., and Arnold, T. M. 2013. Flexible resource allocation during plant defense responses. Front. Plant Sci. 4:324.

Schultz, J. C., and Baldwin, I. T. 1982. Oak leaf quality declines in response to defoliation by gypsy moth larvae. Science 217:149-151.

Schwachtje, J., and Baldwin, I. T. 2008. Why does herbivore attack reconfigure primary metabolism? Plant Physiol. 146:845-851.

Seki, M., Narusaka, M., Ishida, J., Nanjo, T., Fujita, M., Oono, Y., Kamiya, A., Nakajima, M., Enju, A., Sakurai, T., Satou, M., Akiyama, K., Taji, T., Yamaguchi-Shinozaki, K., Carninci, P., Kawai, J., Hayashizaki, Y., and Shinozaki, K. 2002. Monitoring the expression profiles of 7000 Arabidopsis genes under drought, cold and high-salinity stresses using a full-length cDNA microarray. Plant J. 31:279-292.

Shafique, S., Ahmad, A., Shafique, S., Anjum, T., Akram, W., and Bashir, Z. 2014. Determination of molecular and biochemical changes in cotton plants mediated by mealybug. NJAS Wageningen J. Life Sci. 70-71:39-45

Smith, S. E., and Read, D. J. 2010. Mycorrhizal Symbiosis. Academic Press, Cambridge, MA, U.S.A.

Stowe, K. A., Marquis, R. J., Hochwender, C. G., and Simms, E. L. 2000. The evolutionary ecology of tolerance to consumer damage. Annu. Rev. Ecol. Syst. 31:565-595.

Tarkka, M. T., Herrmann, S., Wubet, T., Feldhahn, L., Recht, S., Kurth, F., Mailänder, S., Bönn, M., Neef, M., Angay, O., Bacht, M., Graf, M., Maboreke, H., Fleischmann, F., Grams, T. E. E., Ruess, L., Schädler, M., Brandl, R., Scheu, S., Schrey, S. D., Grosse, I., and Buscot, F. 2013 OakContigDF159.1, a reference library for studying differential gene expression in Quercus robur during controlled biotic interactions: Use for quantitative transcriptomic profiling of oak roots in ectomycorrhizal symbiosis. New Phytol. 199:529-540.

Taylor, A. F. S. 2002. Fungal diversity in ectomycorrhizal communities: Sampling effort and species detection. Plant Soil 244:19-28.

Ton, J., De Vos, M., Robben, C., Buchala, A., Métraux, J.-P., Van Loon, L. C., and Pieterse, C. M. J. 2002. Characterization of Arabidopsis enhanced disease susceptibility mutants that are affected in systemically induced resistance. Plant J. 29:11-21.

van der Heijden, M. G. A., and Sanders, I. R., eds. 2002. Mycorrhizal Ecology. Ecological Studies, Vol. 157. Springer-Verlag, Berlin, Heidelberg, Germany.

Veluthakkal, R., Sundari, B. K. R., and Dasgupta, M. G. 2012. Tree chitinases-Stress- and developmental-driven gene regulation. For. Pathol. 42:271-278.

Volpin, H., Elkind, Y., Okon, Y., and Kapulnik, Y. 1994. A vesicular arbuscular mycorrhizal fungus (Glomus intraradix) induces a defense response in alfalfa roots. Plant Physiol. 104:683-689.

Wang, X., Tang, C., Deng, L., Cai, G., Liu, X., Liu, B., Han, Q., Buchenauer, H., Wei, G., Han, D., Huang, L., and Kang, Z. 2010. Characterization of a pathogenesis-related thaumatin-like protein gene TaPR5 from wheat induced by stripe rust fungus. Physiol. Plant. 139:27-38.

Wiemken, V., and Boller, T. 2002. Ectomycorrhiza: Gene expression, metabolism and the wood-wide web. Curr. Opin. Plant Biol. 5:355-361.

Yao, Q., Zhu, H. H., and Zeng, R. S. 2007. Role of phenolic compounds in plant defense: Induced by arbuscular mycorrhizal fungi. Allelopathy J. 20:1-13.

Young, M. D., Wakefield, M. J., Smyth, G. K., and Oshlack, A. 2010. Gene ontology analysis for RNA-seq: Accounting for selection bias. Genome Biol. 11:R14.

\section{AUTHOR-RECOMMENDED INTERNET RESOURCES}

TrophinOak project: https://www.ufz.de/trophinoak/ SeqClean: https://sourceforge.net/projects/seqclean R Core Group: http://www.r-project.org 